\title{
Archives
}

\section{Introduction aux mémoires sur le renouvellement de la politique culturelle du Québec (2016)}

\section{ELAINE SIROIS}

Volume 47, numéro 2, 2018

\section{MÉMOIRES SUR LE RENOUVELLEMENT DE LA POLITIQUE \\ CULTURELLE DU QUÉBEC (2016)}

URI : https://id.erudit.org/iderudit/1045167ar

DOI : https://doi.org/10.7202/1045167ar

Aller au sommaire du numéro

\section{Éditeur(s)}

Association des archivistes du Québec (AAQ)

ISSN

0044-9423 (imprimé)

2369-9256 (numérique)

Découvrir la revue

Citer ce document

SIROIS, E. (2018). Introduction aux mémoires sur le renouvellement de la politique culturelle du Québec (2016). Archives, 47(2), 43-47.

https://doi.org/10.7202/1045167ar

\section{Résumé de l'article}

En ouverture du dossier spécial de la revue Archives, l'auteure présente les consultations publiques tenues en 2016 par le ministère de la Culture et des Communications (MCC) sur le renouvellement de la politique culturelle québécoise. Les mémoires publiés par la revue, celui de l'Association des archivistes du Québec (AAQ), celui des associations d'archives religieuses - le Comité des archives du Conseil du patrimoine religieux du Québec (CPRQ), Regroupement des archivistes religieux du Québec (RAR) et la Table de concertation des archives religieuses de la région de Montréal (TCARM) - ainsi que celui de l'Église catholique de Québec, témoignent de la mobilisation du milieu en faveur des archives lors de ces consultations. Malgré cela, les archives sont peu présentes dans le projet de nouvelle politique du MCC. L'auteure appelle les archivistes à l'action pour redonner aux archives leur importance dans la culture. 


\section{AVANT-PROPOS}

\section{Introduction aux mémoires sur le renouvellement de la politique culturelle du Québec (2016)}

\section{ELAINE SIROIS}

Directrice, Archives Deschâtelets-NDC

La politique culturelle du Québec a 25 ans. C'est beaucoup! La société a évolué sur le plan culturel, que ce soit en matière de pratiques ou de diversité, sans parler de la mondialisation, des changements démographiques et du développement des technologies (Ministère de la Culture et des Communications du Québec, 2017c). C'est pourquoi le gouvernement du Québec a ressenti le besoin d'actualiser sa politique. Pour ce faire, plusieurs stratégies et consultations publiques ont eu lieu, dont celle du dépôt de mémoires rédigés par des organismes et institutions du milieu culturel. Plusieurs associations et organisations du domaine des archives ont saisi cette occasion de démontrer la place prépondérante qu'occupent les archives dans la vie culturelle québécoise.

La revue Archives a choisi de vous présenter trois de ces mémoires. Pourquoi? Certainement pour leur offrir une meilleure diffusion au sein même d'une clientèle gagnée d'avance, mais surtout pour vous présenter une mise à jour de la situation des archives au Québec et, pourquoi pas, vous proposer des arguments quant au rôle culturel joué par celles-ci. 
Les mémoires que vous lirez dans ce numéro ont été déposés au ministère de la Culture et des Communications du Québec (MCC) pendant l'été 2016. En tout, 430 mémoires ont été déposés provenant de divers milieux culturels, de municipalités, d'associations et de citoyens qui ont à cœur la culture québécoise. Le milieu des archives s'est mobilisé de plusieurs façons. L'Associations des archivistes du Québec a déposé son mémoire, réclamant ainsi une place de choix pour les archives dans la nouvelle politique culturelle, un rôle reconnu pour les archivistes dans la préservation du patrimoine ainsi qu'une refonte de la Loi sur les archives (Association des archivistes du Québec, 2016).

Le domaine des archives religieuses a aussi réagi. Les trois associations reliées à ce domaine se sont regroupées pour présenter un mémoire commun. II s'agit du comité des archives du Conseil du patrimoine religieux du Québec (CPRQ), le Regroupement des archivistes religieux du Québec (RAR) et la Table de concertation des archives religieuses de la région de Montréal (TCARM). Leur mémoire, intitulé Forces vives oubliées de la culture québécoise, réitère la richesse des archives religieuses et présente un état de la situation dans un contexte de décroissance et de vieillissement des membres des communautés religieuses.

Le troisième mémoire, celui de l'Église catholique de Québec, propose une réflexion sur l'importance du patrimoine religieux. L'Église de Québec souhaite entre autres que le MCC intègre explicitement le patrimoine religieux dans sa politique culturelle. Le patrimoine archivistique religieux est présenté comme un témoin du patrimoine immobilier dont il documente les bâtiments, les œuvres d'art et les objets de culte. Les archives rappellent aussi les rites et pratiques religieuses tout en véhiculant le message évangélique (Église catholique de Québec, 2016, p. 3). Parmi ses nombreuses recommandations, I'Église de Québec propose notamment de poursuivre la compilation et la mise à jour des inventaires du patrimoine religieux ainsi que la réalisation d'un état des lieux de ce patrimoine (2016, p. 7). Ce projet pourrait facilement être réalisé par le CPRQ, pour lequel l'Église de Québec recommande d'ailleurs un élargissement de son mandat et de son financement afin qu'il puisse prendre en charge des aspects actuellement non couverts par son programme, dont la conservation et la diffusion du patrimoine archivistique (2016, p. 9).

Suite au dépôt des mémoires et à de nombreuses consultations publiques à travers la province, le MCC propose une ébauche de 
sa nouvelle politique dans le document Partout, la culture, Politique québécoise de la culture, disponible en ligne (2017b). Des consultations publiques sur cette version ont été tenues les 5 et 6 septembre 2017, lors d'un forum national, afin de permettre aux différentes associations du milieu culturel de réagir aux nouvelles orientations (MCC, 2017a). Plusieurs associations étaient présentes lors de ces deux journées: les bibliothécaires, les libraires, les historiens, les muséologues... mais pas les archivistes! Étonnamment, les archives ne semblent pas être associées à la culture et les archivistes ont encore beaucoup de travail à faire, même au niveau gouvernemental, pour se faire valoir en tant qu'acteurs culturels.

Dans son projet de nouvelle politique, un document d'une cinquantaine de pages, le MCC n'évoque qu'à une seule reprise le mot «archives » dans un encart à propos du caractère irremplaçable du patrimoine culturel:

Que l'on parle de paysages, d'immeubles, de patrimoine immatériel, de sites archéologiques, de personnages et d'événements historiques ou encore de collections conservées dans les institutions muséales et les centres $d^{\prime}$ archives, le patrimoine culturel témoigne de l'histoire et de l'évolution de la société. (2017b, p. 27)

Quant au mot « archiviste », il n'apparaît également qu'une seule fois, à la page précédente:

La connaissance, la protection, la valorisation et la transmission du patrimoine culturel sont des responsabilités collectives portées par de multiples intervenants (municipalités, propriétaires d'immeubles, bénévoles, porteurs de tradition, muséologues, archivistes, archéologues, médiateurs, travailleurs des métiers traditionnels du bâtiment, etc.). Tous investissent temps, énergie et argent au bénéfice de l'ensemble de la société québécoise. (2017b, p. 26)

Dans ce projet de politique, le MCC s'engage à soutenir les acteurs culturels dans leur travail. Ce principe est louable, restera à voir s'il s'accompagnera de mesures concrètes. Reconnaissant que l'État québécois est lui-même propriétaire de nombreux documents, il s'engage à les traiter de manière exemplaire pour les transmettre aux générations futures (2017b, p. 26). Cet engagement est rassurant, quoiqu'il n'apporte rien de bien nouveau. 
Ce peu de visibilité des archives dans la nouvelle politique s'expliquet-il, en partie, par la composition du comité scientifique chargé de sa rédaction? Composé de treize membres, il regroupe surtout des gens provenant des milieux de l'architecture et de l'urbanisme. II n'y a pas d'historiens, encore moins d'archivistes. Comment peut-on rédiger une politique culturelle sans le concours d'un historien?

Bien que les archives n'occupent pas une grande place dans ce mémoire, elles y sont tout de même mentionnées. Cependant, encore et toujours, un grand travail de reconnaissance reste à accomplir. Les archives sont souvent au début de la chaîne patrimoniale, préservant des documents sous une variété de supports qui témoignent des origines, des pratiques et des manifestations culturelles d'hier et d'aujourd'hui. Elles sont, par exemple, souvent requises pour des travaux de restauration et de mise en valeur patrimoniales. Les tient-on pour acquises? Elles ont toujours été là et le seront toujours? Elles vivent dans l'ombre, au même titre que leurs archivistes. II est temps de sortir de nos centres d'archives et de nous manifester. C'est ce qu'ont tenté de faire les archivistes qui ont rédigé les mémoires soumis à votre regard dans ce numéro. Continuons d'en parler et de faire valoir la place importante des archives dans la culture québécoise.

ELAINE SIROIS

\section{BIBLIOGRAPHIE}

ASSOCIATION DES ARCHIVISTES DU QUÉBEC. (2016). Renouvellement de la politique culturelle du Québec. Repéré à https://www.mcc. gouv.qc.ca/fileadmin/documents/Politique-culturelle/Memoires Metadonnees/Association des archivistes du Quebec memoirel.pdf

COMITÉ DES ARCHIVES DU CONSEIL DU PATRIMOINE RELIGIEUX DU QUÉBEC (CPRQ), REGROUPEMENT DES ARCHIVISTES RELIGIEUX DU QUÉBEC (RAR) ET TABLE DE CONCERTATION DES ARCHIVES RELIGIEUSES DE LA REGION DE MONTRÉAL (TCARAM). (2016), Forces vives oubliées de la culture québécoise: les archives religieuses. Repéré à https://www.mcc.gouv.qc.ca/fileadmin/documents/Politique-culturelle/ Memoires Metadonnees/Conseil du patrimoine religieux du Quebec_et_Regroupement_des_Archivistes_memoire.pdf 
ÉGLISE CATHOLIQUE DE QUÉBEC. (2016). Mémoire présenté dans le cadre de la consultation publique sur le renouvellement de la politique culturelle du Québec. Repéré à https://www.mcc.gouv.qc.ca/ fileadmin/documents/Politique-culturelle/Memoires Metadonnees/ Archidipcese catholique memoire.pdf

MINISTÈRE DE LA CULTURE ET DES COMMUNICATIONS DU QUÉBEC (MCC). (2017a). Consultation sur le projet de politique québécoise de la culture. Repéré à https://www.mcc.gouv.qc.ca/index.php?id=6120

MINISTÈRE DE LA CULTURE ET DES COMMUNICATIONS DU QUÉBEC (MCC). (2017b). Partout, la culture. Politique québécoise de la culture. Repéré à https://www.mcc.gouv.qc.ca/fileadmin/documents/grands dossiers/PolitiqueQcCulture/PartoutLaCulture.pdf

MINISTÈRE DE LA CULTURE ET DES COMMUNICATIONS DU QUÉBEC (MCC). (2017C). Partout, la culture. Politique québécoise de la culture. Contexte. Repéré à https://www.mcc.gouv.qc.ca/index.php?id=5795 